\title{
HEALTH IMPACTS OF HOUSEHOLD FUELS: GROWING EVIDENCE IN DEVELOPING COUNTRIIES
}

\author{
Kirk R Smith \\ Program on Environment, East-West Center \\ 1777 East-West Road, Honolulu, Hawaii, 96848
}

\begin{abstract}
Although part of human experience since the mastery of fire, indoor air pollution from open combustion of solid fuels, such as wood, crop residues, and untreated coal, has been scientifically characterized only in the last decade. Demonstrated is not only that typical indoor concentrations of important pollutants, such as respirable particulates, carbon monoxide, benzene and formaldehyde, are excessive by comparison to health-based standards, but, since about one-half of humanity still cooks and/or heats with simple solid-fuel stoves, the total population involved is potentially quite large. ${ }^{1}$ Thus, a significant proportion of global human exposure to some air pollutants occurs in these situations. ${ }^{2}$
\end{abstract}

As shown in Table 1, for example, it has been estimated that most of the global air pollution exposure to particulates, the most important single class of pollutants, does not occur outdoors in developed-country cities, where most research and management efforts have focused. Rather, most occurs in the inverse situations, i.e. indoors in developing-country cities and villages. ${ }^{3}$

By extrapolation from urban developed-country epidemiological studies, it is possible to make rough estimates of the potential health impact of such exposures. For example, although particulates have been studied longer than any other outdoor air contaminant, it has been hard to distinguish its effects from those of sulfur oxides, which have usually accompanied it in the developed-country cities where these studies were done. Thus, standards for the two pollutants have often been linked together. In recent years, however, new studies 4.5 and reevaluations of old ones using advanced statistical techniques ${ }^{6}$, have tended to confirm TSP rather than sulfur oxides as the principal bad actor. ${ }^{7.8}$

Of particular relevance to LDC issues is that these studies have tended to show effects on daily mortality at concentrations at or even below the WHO guidelines for TSP; in other words, no threshold is evident. In addition, at least at the lower end of the dose-response curve, there is a significant increase in mortality even with comparatively small increases in ambient concentration, for example, $6 \%, 7 \%{ }^{10}$, and $4 \%{ }^{11}$ increases with $100 \mu \mathrm{g} / \mathrm{m}^{3}$ increase in ambient levels in three separate U.S. studies. The exact meaning of these studies for LDC conditions is clouded because of different populations, different pollutant mixtures, and a different relationship between ambient levels and total exposure (because of different housing and mix of local sources). Nevertheless, given the relatively high concentrations experienced indoors and out in many LDC situations, health effects could be expected, although the dose-response curve may curve over at higher exposures, i.e., there may be less additional ill-health per additional $100 \mu \mathrm{g} / \mathrm{m}^{3}$ at $1000 \mu \mathrm{g} / \mathrm{m}^{3}$ than at $100 \mu \mathrm{g} / \mathrm{m}^{3}$.

Just in the last fewyears, however, a number of epidemiological studies have been published that directly address the risks of indoor exposures to stove pollutants in developing coun-

Table 1. Particulate concentrations and exposures in the eight major global microenvironments. See reference \#3 for derivation of the concentrations, populations, and time budgets.

\begin{tabular}{|c|c|c|c|c|c|}
\hline & \multicolumn{2}{|c|}{ Concentration } & \multicolumn{2}{|c|}{ Exposures } & \multirow[b]{2}{*}{$\begin{array}{c}\text { Total } \\
\%\end{array}$} \\
\hline & $\begin{array}{l}\text { Indoor } \\
\left(\mu \mathrm{g} / \mathrm{m}^{3}\right)\end{array}$ & $\begin{array}{l}\text { Outdoor } \\
\left(\mu \mathrm{g} / \mathrm{m}^{3}\right)\end{array}$ & $\begin{array}{c}\text { Indoor } \\
\%\end{array}$ & $\begin{array}{l}\text { Outdoor } \\
\%\end{array}$ & \\
\hline \multicolumn{6}{|l|}{ Developed } \\
\hline Urban & 100 & 70 & 5 & $<1$ & 6 \\
\hline Rural & 60 & 40 & 1 & $<1$ & 1 \\
\hline \multicolumn{6}{|l|}{ Developing } \\
\hline Urban & 250 & 280 & 19 & 7 & 26 \\
\hline \multirow[t]{2}{*}{ Rural } & 550 & 90 & 62 & 5 & 67 \\
\hline & & Total & 87 & 13 & 100 \\
\hline
\end{tabular}

Note: Population exposures expressed as a percentage of the world total. Here exposure is defined to equal to the number of people exposed multiplied by the duration of exposure and the concentration breathed during that time.

a. This paper will not review the several recent valuable South African indoor air studies relevant to the topic, as they will be presented at other times during the conference. 
tries. Although several health effects have been noted, including chronic lung disease and adverse pregnancy outcome, here, the two largest data sets are reviewed, those dealing with respiratory infections in children and lung cancer in adults.

\section{ACUTE RESPIRATORY INFECTIONS (ARI)}

ARI, principally in the form of pneumonia, is the chief killer of young children worldwide, being responsible for some 4.3 million deaths annually, one-third more than the next category, diarrhea. Developed-country studies have shown ARI in children to be enhanced by exposures to urban air pollutants and indoor environmental tobacco smoke at levels of pollution some 10-20 times less than typical in biomass-burning homes.

The first published study of woodsmoke and ARI in young children was based on examinations of $150 \mathrm{Zulu}$ infants coming to a South African hospital. ${ }^{12}$ Children living in homes with woodstoves were almost five times as likely to develop a severe enough ARI to be hospitalized. In Nepal, Pandey et al. 13 examined about 240 rural children under 2 years old for 6 months and found a significant relationship between number of hours spent near the fire (as reported by the mother) and the incidence of ARI cases.

In Zimbabwe, 244 children under 3 years old reporting to a hospital with lower respiratory disease were compared to 500 similar children reporting to a Well Baby Clinic. ${ }^{14}$ Compared to stoves using modern fuels such as kerosene and bottled gas, woodstoves were more likely to be reported at the homes of ill children. Overall, the risk of ARI was increased by a statistically significant factor of more than two for children living in homes where cooking was done on an open biomass stove.

In a study of 500 children in The Gambia, girls under 5 years of age who were carried on their mother's back during cooking (in smoky cooking huts) were found to have a six times higher risk of ARI, a substantially higher risk factor than parental smoking. ${ }^{15}$ Oddly, there was no significant risk for young boys, perhaps because they tended to be carried for shorter periods. For infants, however, the risk for boys and girls together was almost three. The investigators adjusted their risk estimates (multivariate analysis) mathematically to reduce the chance that the risks they found were due to some other factors, such as ethnic group, socioeconomic status, nutritional status, and so on.

There have also been studies in Southeast Asia of ARI in children that failed to show a smoke effect. These have been done with school-age children, however, who are not at such high risk of serious ARI.

Current evidence seems to indicate that exposure to woodsmoke from cookfires in poorly ventilated conditions might increase by $100-400 \%$ the chance for a young child to have a serious case of ARI. This means that, in areas where ARI poses a significant hazard, a large number of young children could be affected. Needed are intervention studies with exposure monitoring to see whether ARI rates can be reduced by introduction of practical exposure-reduction methods, such as improved stoves with chimneys.

\section{LUNG CANCER}

Although biomass smoke contains known carcinogens, such as polyaromatic hydrocarbons, few studies have focuced on its actual cancer risk. Lung cancer in nonsmoking women in Osaka, however, was found to be a significant risk factor in older women who had been cooking with biomass at age $30 .{ }^{16}$

For coal smoke, however, a number of ecologic and casecontrol studies have been done, nearly all in China. ${ }^{17}$ There is, for example, a correlation $(r=0.7)$ between latitude and women's lung cancer rates in 16 Chinese cities. For men, the correlation was smaller $(r=0.2)$ and not statistically significant. Niether gender showed a trend with latitude for bladder cancer. In addition, the men/women ratio declined with latitude, reaching levels as low as anywhere else in the world. Overall, women had a much higher proportion of adenocarcinoma than men. Among other possibilities (smoking, diet, respiratory infections, outdoor air possution), the latitudinal, gender, and cancer-site patterns in China are most consistent with indoor air pollution from coal heating as a risk factor.

Although it is difficult to establish the decades-long personal histories needed for determining relevant exposures, the weight of nearly a dozen studies indicates a significant lung cancer risk: 2-6 for urban women cooking/heating for long periods with coal compared to those using gas (Figure 1). Rural coal smoke exposures, which have been higher, seem to produce risks up to nine. There are also intriguing indications that the risk may vary substantially by type of coal and with the type of vegetable oil used to fry foods.

These findings plus much additional work in China on other health impacts ${ }^{18}$ should be considered carefully by other countries now using or planning to use coal as household fuel.

\section{CONCLUSION}

Besides giving direction for further research, these studies indicate that the scale of health impact from indoor pollution in developing countries may be substantial compared to that from other pollution exposures. For this reason, the World Bank in 1992 classed it among the four most critical global environmental problems. ${ }^{19}$ There are important implications for health, energy, housing and environmental policies.

\section{REFERIENCES}

1. Smith, KR Biofuels, Air Pollution and Health: A Global Review, Plenum, New York, 1987.

2. Smith, K R Total exposure assessmsent, Environment 30(10): 16, 1988.

3. Smith, KR Fuel combustion, air pollution and health, 
Annual Review of Energy and Environment, 18:529, 1993.

4. Pope, C A, Dockery, D W Acute health effects of PM10 on symptomatic and asymptomatic children. Am. Rev. Resp. Dis. 145:1123, 1992.

5. Portney, P R, Mullahy, J Urban air quality and chronic respiratory disease. Region. Sci. \& Urban Econ. 20(3):407, 1990.

6. Schwartz, J, Marcus A Mortality and air pollution in London: A time series analysis. Am. J. Epidemiology $\underline{131: 185,1990 .}$

7. Ozkaynak, H, Thurston, GD Associations between 1980 U S mortality rates and alternative measure of airborne particle concentration. Risk Analysis 7(4):449, 1987.

8. Spengler, JD, et al. Acid air and health. Environ. Sci. Technol. 24(7):946, 1990

9. Schartz, J Particulate air pollution and mortality in Detroit. Environ. Res. 56:294, 1991.

10. Schwartz, J, Dockery, D W Increased mortality in Philadelphia associated with daily air pollution concentrations. Am. Rev. Resp. Dis. 145:600, 1992.

11. Schwartz, J, Dockery D W Particulate air pollution and daily mortality in Steubenville, Ohio. Am. J. Epidemiology 135:12, 1992.

12. Kossove, D Smoke-filled rooms and respiratory disease in infants. So. African Med. J. 63:622, 1982.

13. Pandy, $M R$, et al. Domestic smoke pollution and acute respiratory infections in a rural community Environ. Internat. 15:337,1989.

14. Collings, D A Indoor woodsmoke pollution causing lower respiratory disease in children Tropical Doctor 20:151, 1990.

15. Armstrong, $\mathrm{R} \mathrm{W}$, Campbell $\mathrm{H}$ Indoor air pollution and lower respiratory infection in children Int. J. Epidemiology 20:424, 1991.

16. Subue, $\mathrm{T}$ Association of indoor pollution and lifestyle with lung cancer in Osaka Int. J. Epidemiology 19)(supl 1):s62, 1990.
17. Smith, $\mathrm{K} R$, Liu, $\mathrm{Y}$ Indoor air pollution in developing countries, J Samet (ed.). The Epidemiology of Lung Cancer, Marcell Dekker, New York, 1993 (in press), p. 151.

18. Chen, $\mathrm{BH}$ et al. Indoor air poll. in developing countries, WHO Stat. Quart. 43:172, 1990.

19. World Bank, World Development Report, Oxford, New York, 1992.

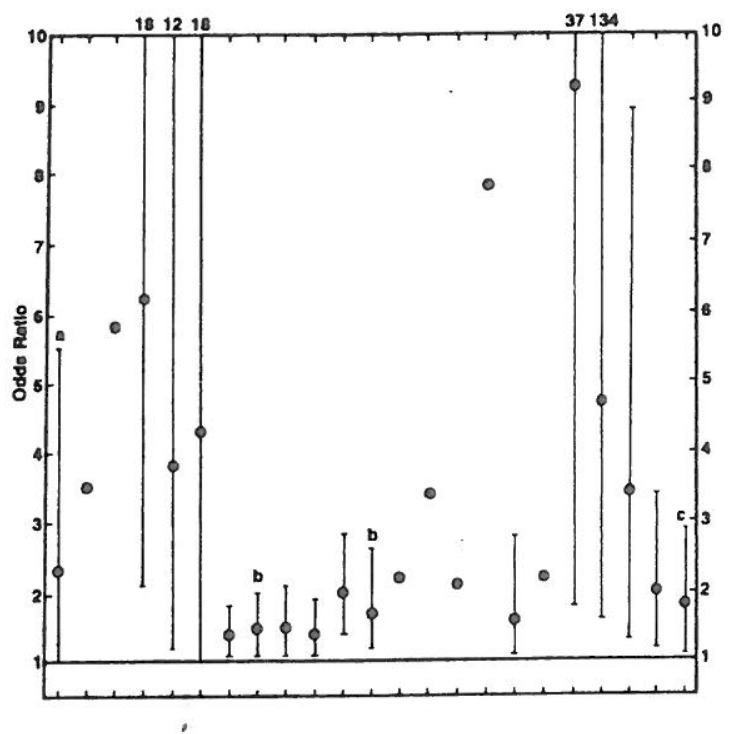

1. Summary of coal smoke and lung cancer studies. The points represent the best estimates of the odds ratios for each exposure indicator. The lines above andbelow most points indicate the $95 \%$ confidence intervals. By convention, odds ratios for which the $95 \%$ confidence interval does not cross 1.0 are termed statistically significant. Except for the first (a), which is a study of people in Los Angeles who had been exposed to coal heating in their childhood, and the two marked (b), which are from a study that found a relationship between cooking with rapeseed oil and lung cancer, and the last (c), which is a Japanese study of women who cooked with wood when they were 30 years old, all of the points represent studies of coal smoke exposures in China. 